\title{
Michael Screech (1926-2018)
}

\section{Frank Lestringant}

\section{(2) OpenEdition}

\section{Journals}

\section{Édition électronique}

URL : http://journals.openedition.org/studifrancesi/16054

DOI : 10.4000/studifrancesi. 16054

ISSN : 2427-5856

\section{Éditeur}

Rosenberg \& Sellier

\section{Édition imprimée}

Date de publication : 1 juillet 2019

Pagination : 3-4

ISSN : 0039-2944

\section{Référence électronique}

Frank Lestringant, " Michael Screech (1926-2018) », Studi Francesi [En ligne], 187 (LXIII | I) | 2019, mis en ligne le 01 avril 2020, consulté le 25 janvier 2021. URL : http://journals.openedition.org/ studifrancesi/16054; DOI : https://doi.org/10.4000/studifrancesi.16054

\section{(c) $\odot \Theta \Theta$}

Studi Francesi è distribuita con Licenza Creative Commons Attribuzione - Non commerciale - Non opere derivate 4.0 Internazionale. 


\section{Michael Screech \\ (1926-2018)}

Michael Screech, l'un des meilleurs connaisseurs de la littérature française de la Renaissance, spécialiste de Rabelais aussi bien que de Marot et de Montaigne, s'est éteint à Oxford le $1^{\text {er }}$ juin 2018 à l'âge de 92 ans. Le matin de ce même jour, je m'entretenais de lui avec Neil Kenny sur le campus de l'Université de Lille à l'occasion d'un colloque sur «Les métaphores du livre à la Renaissance». Ses dernières années avaient été assombries par le décès de son épouse Anne, qu'il avait soignée avec patience et sollicitude.

Né à Plymouth le 2 mai 1926 dans une famille méthodiste, Michael Screech était le plus jeune fils d'un policier, d'un policeman, devrait-on dire. Son principal fait d'arme fut l'apprentissage du japonais pour l'Intelligence Service, mais lorsqu'il débarqua au Japon, âgé de dix-neuf ans, en février 1946, la guerre était terminée. Ce qui ne l'empêcha pas de séjourner dans l'archipel nippon, améliorant sa connaissance du japonais, qu'il parlait à la perfection.

«J'ai vécu avec lui toute ma vie d'adulte», disait-il de Rabelais. Adolescent, il le lisait déjà en anglais pendant le «blitz». Plus tard, il le relut en français pendant son interminable service militaire, en Angleterre, en Inde et enfin au Japon. Comme il le dit très justement, «les alliés n'avaient pas le monopole de ce génie». Au Japon Kazuo Watanabe traduisait Rabelais au milieu d'une guerre dont il prévoyait la fin catastrophique 1 . C'est ainsi que Gargantua fut publié en japonais en 1943, dans une traduction sensible au «côté lumineux, optimiste et rationaliste de Rabelais comme champion de la Renaissance française» ${ }^{2}$.

De retour en Angleterre, Michael Screech gravit les échelons académiques, assistant à l'Université de Birmingham en 1951, dix ans plus tard à l'University College de Londres, devenant en 1971 Fielden Professor de langue et littérature françaises, et enfin membre d'All Souls College à Oxford.

Ses premiers travaux universitaires portaient déjà sur Rabelais, L'Évangélisme de Rabelais. Aspects de la satire religieuse au XVI siècle (Genève, Droz, 1959), et sur Clément Marot, Marot évangélique (Droz, 1967). S'ensuivirent Rabelais et le mariage. Religion, morale et philosophie du rire (Droz, 1992) et son monumental Rabelais de 1979, dont la traduction fut publiée en 1992 chez Gallimard dans la «Bibliothèque des idées». Contrairement à ce que l'on a longtemps répété, Rabelais n'était nullement un esprit fort, moins encore un athée, mais un évangélique convaincu refusant fermement de s'engager dans une intransigeante Réforme. De même Marot, moins fantasque et moins libertin qu'il ne semble, était adepte d'une foi conforme à l'Évangile et c'est le

(1) M.A. SCREECH, Introduction. Sagesse de Rabelais. Rabelais et les "bons christians", in Rabelais en son demi-millénaire. Actes du colloque international de Tours (24-29 septembre 1984), publiés par Jean Céard et Jean-Claude Margolin, Genève, Droz, «Etudes rabelaisiennes», t. XXI, 1988, pp. 9-10.

(2) S. ARAKI, Les contributions aux études rabelaisiennes d'un bumaniste japonais: Kazuo Watanabe (1901-1975), in Rabelais en son demi-millénaire cit., pp. 381-387. 
sens que l'on peut prêter à sa traduction des Psaumes en vers français. Dans les mêmes années, en collaboration avec Stephen Rawles, Michael Screech établit une bibliographie exhaustive des éditions de Rabelais avant 1626, forte de près de 700 pages $^{3}$.

À l'âge de 67 ans, parvenu à la retraite, Michael Screech avait été ordonné pasteur de l'église d'Angleterre. Pasteur anglican, il émaillait ses sermons dominicaux de citations de Rabelais, citations que, toujours souriant, il donnait en français puis en anglais. C'est alors qu'il traduisit Les Essais de Montaigne, déjà bien connus en Angleterre depuis le début du XVII ${ }^{\mathrm{e}}$ siècle par la translation de John Florio. Il ajouta à sa traduction alerte des notes savoureuses et savantes, le tout publié chez Penguin en 1991. Même chose pour Rabelais, dont il traduisit ou adapta les cinq livres dans une édition au format de poche abondamment annotée.

En France même, Michael Screech n'était pas un inconnu. Fait chevalier de la légion d'honneur en 1992, il était un familier de nos bibliothèques et aussi de nos colloques, qu'il ne goûtait guère pourtant. Je le rencontrai pour la première fois à Tours en septembre 1984, à l'occasion du colloque «Rabelais en son demi-millénaire», qu'il présidait et où il eut la désagréable surprise d'entendre un Américain déclarer que Rabelais était illisible. Cette injure le fit sortir de la salle, et je le croisai seul au détour d'un couloir, ressassant avec amertume cette fâcheuse incompréhension.

L'après-midi du 3 octobre 2003 à Paris, il prit la parole en Sorbonne, à l'amphi Michelet, à l'invitation de Mireille Huchon. Le barbu et chevelu Claude Gaignebet était dans la salle et ne put s'empêcher d'intervenir avec éclat, fustigeant comme à l'ordinaire les rabelaisants érudits et plus savants que lui. Comme il se devait, Michael Screech répondit avec calme et modération. Le soir un dîner eut lieu à Montmartre, place du Tertre, à la Crémaillère. Michael Screech, très disert, était entouré de quelques universitaires français, dont Jean Céard et Guy Demerson.

Le lendemain, il prenait part à un colloque qui se tenait à l'Académie universelle de Montmartre, sise 9, rue Duc, dans une modeste salle. «Rabelais et les mythes», tel était le thème de ce colloque ouvert au grand public et qui recevait une clientèle de quartier. Michael Screech intervenait à tout moment avec courtoisie, plein de fougue et de bienveillance pour l'auditoire qui nous écoutait. C'est lors du dîner qui suivit, au restaurant-glacier «La Banquise» rue Ordener, qu'il évoqua son séjour d'après guerre au Japon et l'injustifiable catastrophe d'Hiroshima, qu'il ne pouvait que déplorer. Je le raccompagnai à l'hôtel des Olympiades, square de Clignancourt, là où nous habitions. Le lendemain dimanche, il me téléphona pour me remercier et prendre congé. Deux semaines plus tard, le dimanche 19 octobre, il était de retour parmi nous avec son épouse Anne, me dédicaçant d'une plume véloce, avant de passer à table, un verre de vin à la main, son édition de Lucrèce annoté par Montaigne.

Je revis Michael Screech avec son épouse trois ans plus tard à Oxford, le 16 février 2006, à l'occasion d'un dîner festif à Wolfson College. Sa gentillesse, son humour, sa science infinie et son extrême courtoisie allaient de pair avec une réelle jovialité. Comment ne pas l'aimer? Ses dernières années furent remplies par son pastorat, et par ses traductions de Rabelais et de Montaigne en paperback. Jusqu'aux derniers mois de sa vie, il entretint sa connaissance du japonais par des lectures quotidiennes. Et jusqu'au bout il relut Rabelais, son compagnon de toujours.

FRANK LESTRINGANT Sorbonne Université t. XX, 1987. 